\title{
Dysregulated Glycine Signaling Contributes to Increased Impulsivity during Protracted Alcohol Abstinence
}

\author{
[Cristina Irimia, ${ }^{1}$ Matthew W. Buczynski, ${ }^{1,2}$ Luis A. Natividad, ${ }^{1}$ Sarah A. Laredo, ${ }^{1}$ Nathaniel Avalos, ${ }^{1}$ \\ and Loren H. Parsons ${ }^{1, \dagger}$ \\ ${ }^{1}$ Committee on the Neurobiology of Addictive Disorders, The Scripps Research Institute, La Jolla, California 92037, and ${ }^{2}$ Virginia Tech School of \\ Neuroscience, Blacksburg, Virginia 24061
}

\begin{abstract}
Persons with alcoholism who are abstinent exhibit persistent impairments in the capacity for response inhibition, and this form of impulsivity is significantly associated with heightened relapse risk. Brain-imaging studies implicate aberrant prefrontal cortical function in this behavioral pathology, although the underlying mechanisms are not understood. Here we present evidence that deficient activation of glycine and serine release in the ventral medial prefrontal cortex (vmPFC) contributes to increased motor impulsivity during protracted abstinence from long-term alcohol exposure. Levels of 12 neurotransmitters were monitored in the rat vmPFC during the performance of a challenging variant of the five-choice serial reaction time task (5-CSRTT) in which alcohol-exposed rats exhibit excessive premature responding. Following long-term ethanol exposure, rats showed blunted task-related recruitment of vmPFC glycine and serine release, and the loss of an inverse relationship between levels of these neurotransmitters and premature responding normally evident in alcohol-naive subjects. Intra-vmPFC administration of the glycine transport inhibitor ALX5407 prevented excessive premature responding by alcohol-exposed rats, and this was reliant on NMDA glycine site availability. Alcohol-exposed rats and controls did not differ in their premature responding and glycine and serine levels in vmPFC during the performance of the standard 5-CSRTT. Collectively, these findings provide novel insight into cortical neurochemical mechanisms contributing to increased impulsivity following long-term alcohol exposure and highlight the NMDA receptor coagonist site as a potential therapeutic target for increased impulsivity that may contribute to relapse risk.
\end{abstract}

Key words: alcohol dependence; five-choice serial reaction time task; glycine; motor impulsivity

Significance Statement

Persons with alcoholism demonstrate increased motor impulsivity during abstinence; however, the neuronal mechanisms underlying these behavioral effects remain unknown. Here, we took advantage of an animal model that shows deficiencies in inhibitory control following prolonged alcohol exposure to investigate the neurotransmitters that are potentially responsible for dysregulated motor impulsivity following long-term alcohol exposure. We found that increased motor impulsivity is associated with reduced recruitment of glycine and serine neurotransmitters in the ventromedial prefrontal cortex (vmPFC) cortex in rats following long-term alcohol exposure. Administration of glycine transport inhibitor ALX5407 in the vmPFC alleviated deficits in impulse control.

\section{Introduction}

Alcoholism is associated with significant disruptions in executive function that contribute to loss of control and relapse (Jentsch

Received Aug. 2, 2016; revised Jan. 3, 2017; accepted Jan. 9, 2017.

Author contributions: C.I. and L.H.P. designed research; C.I., S.A.L., and N.A. performed research; M.W.B. and L.A.N. contributed unpublished reagents/analytictools; C.I. and L.H.P. analyzed data; C.I. and L.H.P. wrote the paper.

These studies were supported by National Institutes of Health Grants R01-AA-022249 and P60-AA-006420. This article is dedicated to the memory of Dr. Loren H. Parsons, who passed away unexpectedly on June 21, 2016, while this work was in progress. Dr. Parsons was an extraordinary mentor and friend, and he contributed greatly to the understanding of the neurochemical basis for alcoholism.

${ }^{\dagger}$ Deceased, June 21, 2016.

The authors declare no competing financial interests. and Taylor, 1999; Duka et al., 2011a; Goldstein and Volkow, 2011). Increased impulsivity contributes to binge drinking and long-term use (Weafer et al., 2014) and is associated with heightened relapse risk (Bowden-Jones et al., 2005; MacKillop and Kahler, 2009; Loree et al., 2015). Persons with alcoholism who have undergone detoxification exhibit increased impulsivity in tasks that index the capacity for response inhibition (Duka et al., 2003; Kamarajan et al., 2005; Rubio et al., 2008; Lawrence et al.,

Correspondence should be addressed to Dr. Cristina Irimia, Stanford University, Department of Biology, 1050 Arastradero Road, Building B, Palo Alto, CA 94304. E-mail: cristin4@stanford.edu.

DOI:10.1523/JNEUROSCI.2466-16.2017

Copyright $\odot 2017$ the authors $\quad 0270-6474 / 17 / 371853-09 \$ 15.00 / 0$ 
2009; Salgado et al., 2009), an effect that is most prevalent following several weeks of abstinence (Stavro et al., 2013) when relapse risk is high (Moos and Moos, 2006).

The restraint of improper responses relies on the function of the ventral medial prefrontal cortex (vmPFC; Iversen and Mishkin, 1970; Swick et al., 2011). In persons with alcoholism, these regions exhibit reduced volumes (Fein et al., 2002; Duka et al., 2011b) and aberrant activation during response inhibition tasks (Li et al., 2009). While compensatory activation of other brain regions allows persons with alcoholism to perform simple tasks at levels similar to those of persons without alcoholism (Chanraud et al., 2013), performance of more challenging tasks is impaired (Noël et al., 2001; Chanraud et al., 2013). Despite knowledge of regional disruptions in cortical function associated with long-term alcohol use (Sullivan and Pfefferbaum, 2005), the neurochemical underpinnings of dysregulated impulse control have not been elucidated.

Animal models provide an essential tool for elucidating the mechanisms underlying impaired impulse control associated with long-term alcohol exposure. The five-choice serial reaction time task (5-CSRTT) is particularly well suited for translating animal studies to the human condition, as this task has uncovered increased motor impulsivity (premature responding) in rodents undergoing protracted ethanol (EtOH) abstinence (Walker et al., 2011; Irimia et al., 2015) and in detoxified alcohol-dependent and binge-drinking humans (Sanchez-Roige et al., 2014; Voon et al., 2014). Following a month of abstinence, EtOH-dependent rodents adequately perform the standard version of the 5-CSRTT but display increased motor impulsivity under conditions of enhanced cognitive load during the challenge task (Walker et al., 2011; Irimia et al., 2014; Irimia et al., 2015). Likewise, alcoholdependent humans display delayed emergence of impulsivity during abstinence (Stavro et al., 2013) that is most evident in cognitively challenging tasks (Moselhy et al., 2001; Noël et al., 2001; Jung et al., 2014).

The neural mechanisms mediating the constraint of waiting impulsivity in the 5-CSRTT are not fully understood. Lesions of the vmPFC increase motor impulsivity as evaluated by the standard 5-CSRTT (Chudasama et al., 2003), and NMDA receptor antagonism in this region results in excessive premature responding (Murphy et al., 2012), suggesting an important role for the vmPFC and NMDA signaling in the constraint of motor impulsivity in this task. Less is known about the specific neurotransmitter signals that are important for proper response inhibition during more cognitively challenging variants of the 5-CSRTT or following long-term EtOH exposure and abstinence.

The present study investigates neurochemical mechanisms in the vmPFC that underlie increased impulsivity during protracted abstinence from long-term EtOH exposure. We used in vivo microdialysis and mass spectrometry to quantify changes in 12 neurotransmitters evoked in the vmPFC during performance of a more challenging version of the 5-CSRTT task (Song et al., 2012; Buczynski et al., 2016). In rodents, repeated exposure to EtOH results in structural damage (Crews and Boettiger, 2009; Crews and Nixon, 2009), upregulation of NMDA-mediated activity (Kroener et al., 2012), and functional impairment (Holmes et al., 2012) in the vmPFC. Thus, we hypothesized that neurotransmitters that signal through the NMDA receptor will be reduced in the vmPFC of EtOH-dependent rats, but not of controls. Our analytical approach allowed us for the first time to measure extracellular levels of multiple neurotransmitters previously implicated in impulse control as well as several novel candidates.

\section{Materials and Methods}

Subjects. Male Wistar rats (71 rats; weight, 250 g; Charles River Laboratories) were housed two per cage on a $12 \mathrm{~h}$ circadian cycle (lights off at 10:00 AM). With the exception of $7 \mathrm{~d}$ of postsurgical recovery and $\mathrm{EtOH}$ vapor exposure, rats were maintained at $90 \%$ of free feeding weight to enable 5-CSRTT performance. All procedures strictly adhered to the National Institutes of Health Guide for Care and Use of Laboratory Animals and were approved by The Scripps Research Institute Institutional Animal Care and Use Committee.

Five-choice serial reaction time task: standard and challenge sessions. All 5-CSRTT training and testing was performed as previously described (Irimia et al., 2015). Standard sessions were composed of 100 trials with a $2 \mathrm{~s}$ visual stimulus duration, a $2 \mathrm{~s}$ limited hold, and a $5 \mathrm{~s}$ intertrial interval (ITI). Performance was indexed as follows: (1) response accuracy $[100 *$ correct/(correct + incorrect)] responses, an index of attentional capacity); (2) premature responses (failure to withhold responding during the ITI, an index of impulsive action); (3) perseverative responses; (4) omissions (index of ability to complete the task or motivation); (5) latency to correct response (index of information processing speed); and (6) feeder latency (index of motivation). Challenge sessions had the same parameters as the standard task, with the exception of the ITI, which was varied pseudorandomly among 5, 7, 9, and $11 \mathrm{~s}$; and the stimulus duration, which was $1 \mathrm{~s}$. All rats received standard 5-CSRTT training. Twentyseven rats were tested under the challenge conditions, and 12 rats were tested under standard conditions during in vivo microdialysis sampling. Figure $1 C$ depicts the experimental time line.

Long-term intermittent EtOH exposure. Rats were housed two per cage in inhalation chambers and exposed to $\mathrm{EtOH}$ vapor (EtOH group) or air (CON) $12 \mathrm{~h} / \mathrm{d}$ for 4 weeks. Blood alcohol levels (BALs) were determined one time per week (Analox Instrument). This procedure has been shown to induce dependence (Schulteis et al., 1995; George et al., 2014) and to result in significant increases in motor impulsivity during abstinence (Irimia et al., 2014, 2015).

In vivo microdialysis. Rats were stereotaxically implanted with a unilateral vmPFC microdialysis guide cannula [PlasticsOne; anteroposterior (AP), $+3.0 \mathrm{~mm}$ from bregma; mediolateral (ML), $\pm 0.75 \mathrm{~mm}$ from breg$\mathrm{ma}$; dorsoventral (DV), -4.2 from dura; probe extension, $1 \mathrm{~mm}]$. Once stable 5-CSRTT performance was re-established, neurochemical collection was performed by in vivo microdialysis as previously described (Caillé et al., 2007). Briefly, probes were implanted in the guide cannula and were subsequently perfused with artificial CSF overnight at $0.1 \mu \mathrm{l} /$ $\mathrm{min}$. The following day, the flow rate was increased to $0.6 \mu \mathrm{l} / \mathrm{min}$, and samples were collected at $5 \mathrm{~min}$ intervals before and during the 5-CSRTT sessions. The six baseline samples before the beginning of the test session correspond to -30 to 0 min time points in Figure 1 (and see Figs. 3, 5). After the last baseline sample was collected, the animal was placed in the 5-CSRTT box, and the session started. The first sample corresponding to the first 5 min of the task was collected at the 5 min time mark. Dialysate levels of glycine, serine, aspartate, glutamate, GABA, dopamine, norepinephrine, serotonin, acetylcholine, taurine, histamine, and glutamine were quantified by liquid chromatography-tandem mass spectrometry (LC-MS/MS; Song et al., 2012; Buczynski et al., 2016). The analytical method used cannot distinguish between D-serine and L-serine. Following the session, brains were snap frozen and analyzed for probe placement.

Drug treatment by site-specific infusion. Rats were stereotaxically implanted with a bilateral vmPFC guide cannula for intracranial infusion (AP, +3.0 from bregma; $\mathrm{ML}, \pm 0.75$ from bregma; $\mathrm{DV},-1.9$ from dura; injector extension, $2.5 \mathrm{~mm}$ ). Once stable 5-CSRTT performance was re-established, rats were site-specifically treated with vmPFC infusions of vehicle (20\% DMSO, 20\% Emulphor, 60\% Saline; $0.6 \mu l, n=16$ rats), the glycine transport inhibitor ALX5407 ( $2 \mathrm{ng} /$ side, Sigma-Aldrich; $n=$ 16 rats; Atkinson et al., 2001) and/or the glycine site NMDA receptor antagonist L-701,324 ( $2 \mathrm{ng} / \mathrm{side}$, Santa Cruz Biotechnology; $n=5$ rats; Vengeliene et al., 2005). Intra-vmPFC infusions $(0.6 \mu \mathrm{l}$ over $2 \mathrm{~min}$, injectors removed $2 \mathrm{~min}$ after infusion) were administered $90 \mathrm{~min}$ before behavioral testing. Following the session, brains were snap frozen and analyzed for cannula placement. 
A

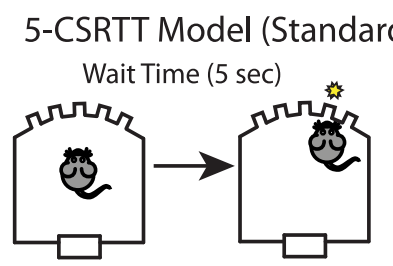

Task initiation

\section{B}

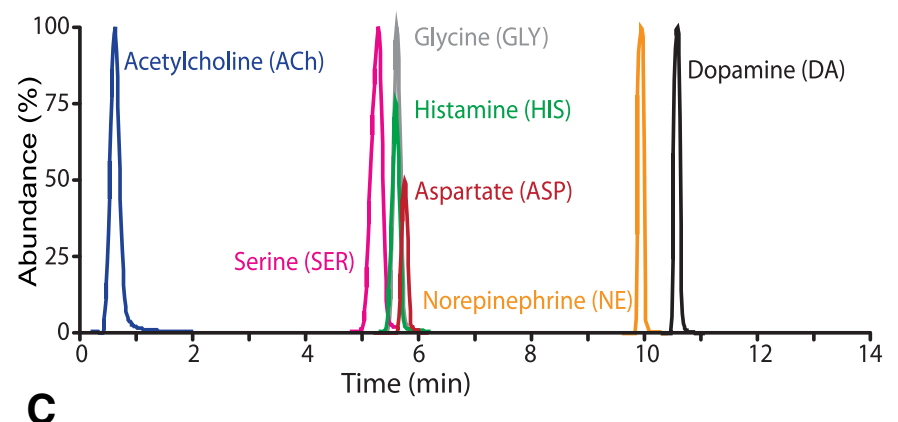

Experiment timeline

\begin{tabular}{|c|c|c|c|}
\hline 5-CSRTT training & & $\begin{array}{l}\text { exposure } \\
4 \text { wks) }\end{array}$ & $\begin{array}{l}\text { Std 5-CSRTT sessions } \\
\text { Abstinence ( } 4 \text { wks) }\end{array}$ \\
\hline \multicolumn{4}{|c|}{ Microdialysis session timeline } \\
\hline \multicolumn{2}{|c|}{$\begin{array}{l}30 \text { min pre-session } \\
\text { baseline sample collection }\end{array}$} & \multicolumn{2}{|c|}{$\begin{array}{l}30 \text { min Challenge or Standard 5-CSRTT } \\
\text { \& sample collection }\end{array}$} \\
\hline
\end{tabular}

Premature resp. (<Wait Time)

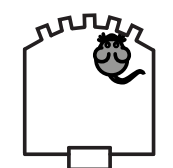

Correct resp. (>Wait time) or i.c. test
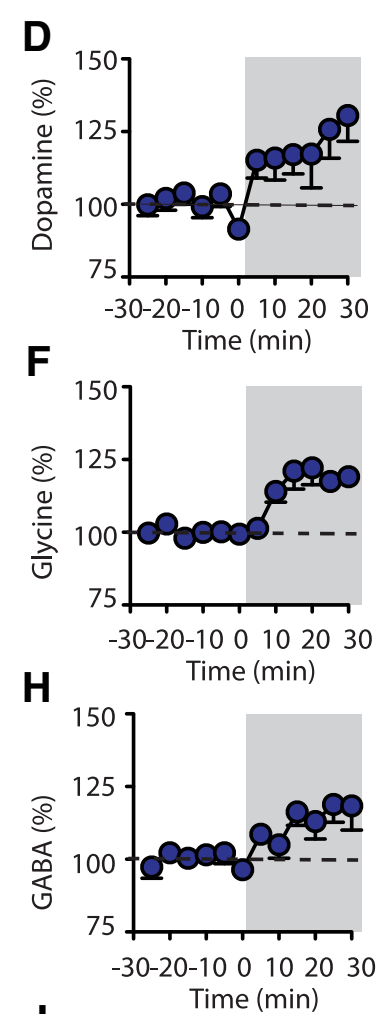

Microdialysis

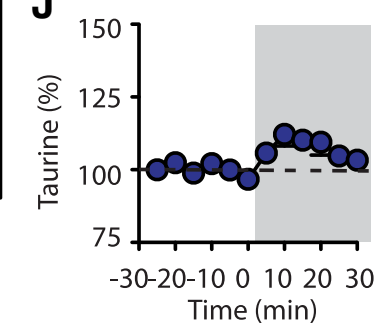

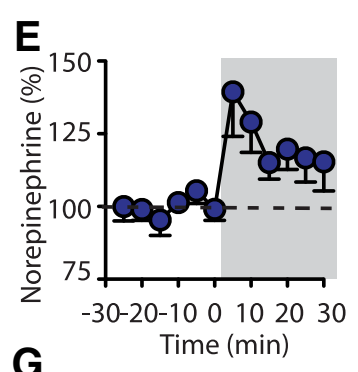

G
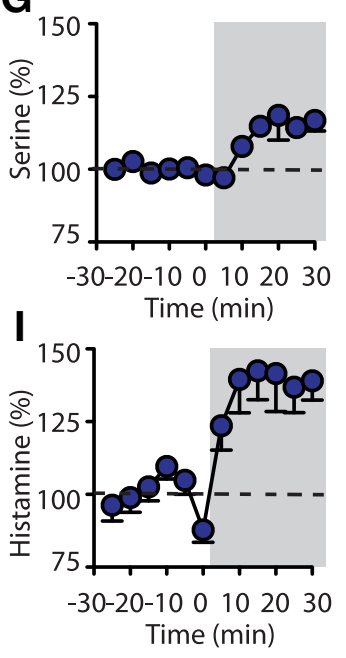
in one of five apertures (middle). Nose poke in the correct aperture results in food reward. Premature responses (e.g., during the intertrial interval) are not rewarded and provide an index of motor impulsivity (right). In the challenge task, the wait time is varied randomly between $5,7,9$, and $11 \mathrm{~s}$. $\boldsymbol{B}$, vmPFC microdialysates collected before and during 5 -CSRTT performance were analyzed by LC-MS/MS for levels of 12 neurotransmitters. $\boldsymbol{C}$, The time line of experiments is depicted. Performance of the challenge task changes the neurotransmitter profile in the vmPFC in CON rats. $\boldsymbol{D}-\boldsymbol{J}$, Task performance resulted in significant elevations in vmPFC dialysate dopamine $(\boldsymbol{D})$, norepinephrine $(\boldsymbol{E})$, glycine $(\boldsymbol{F})$, serine $(\boldsymbol{G}), \mathrm{GABA}(\boldsymbol{H})$, histamine $(\boldsymbol{I})$, and taurine $(\boldsymbol{J})$ in $\mathbf{C O N}$ rats. Neurotransmitter temporal profiles show the percentage change from baseline during the 5-CSRTT session. Samples collected during the 5-CSRTT session are shown on a light gray background.

Statistical analyses. All data were analyzed using the PASW package (SPSS, version 18.0). Before chronic intermittent ethanol (CIE) exposure, the behavioral performance of the two groups (CON and preEtOH) was evaluated using a one-way ANOVA comparison for all behavioral indices calculated as the average of the last $5 \mathrm{~d}$. The effect of CIE on standard task performance following long-term EtOH exposure was evaluated using a repeated-measures (RM) ANOVA with time (abstinence weeks 2, 3, and 4) as the within-subjects factor and group (CON, $\mathrm{EtOH}$ ) as between-subjects factors. Behavioral performance during the challenge task following CIE exposure and abstinence was evaluated with a one-way ANOVA with group $(\mathrm{CON}, \mathrm{EtOH})$ as a factor for all behavioral indices. To test whether premature responses change during the course of the challenge task, we binned responses in six 5 min bins and conducted a two-way ANOVA with time (six bins) as a within-subjects factor and group $(\mathrm{CON}, \mathrm{EtOH})$ as a between-subjects factor. Group differences in baseline neurotransmitter levels were examined by oneway ANOVA with group $(\mathrm{CON}, \mathrm{EtOH})$ as the between-subjects factor. Neurotransmitter levels were expressed as nanomolar concentrations averaged over the six presession baseline samples. Analysis of overall task-related changes in vmPFC neurotransmitter levels was made using area under the curve (AUC) measures, which were obtained by subtracting the average baseline concentration from individual sample concen-
A

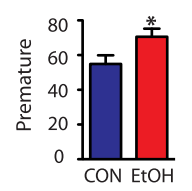

B

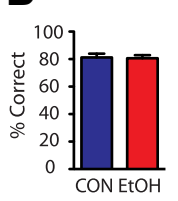

D

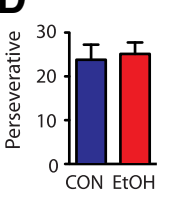

E

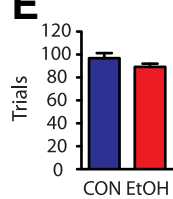

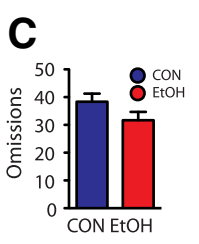

$\mathbf{F}$

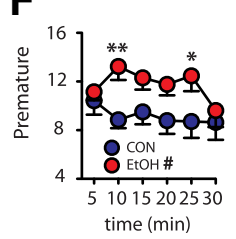

Figure 2. Challenge 5-CSRTT disrupts performance in EtOH-exposed rats. A 5-CSRTT challenge task was used to evaluate the behavior of drug-naive ( $\mathrm{CON}, n=14)$ and $\mathrm{CIE}$ rats (EtOH, $n=13)$. $\boldsymbol{A}-\boldsymbol{E}$, Rats with a history of CIE exposure made more $(\boldsymbol{A})$ premature responses than CON rats, but did not differ in terms of accuracy $(\boldsymbol{B})$, omissions $(\boldsymbol{C})$, perseverative responses $(\boldsymbol{D})$, or total trials $(\boldsymbol{E})$. $\boldsymbol{F}$, Time course of premature responses during the session. 
tration levels and summing the resultant values obtained during task performance. Changes in neurotransmitter levels over time as CON rats engaged in the challenge task were evaluated by one-way ANOVA with time (12 total 5 min bins; 6 bins of baseline and 6 bins of challenge task samples) as a within-subjects factor. The effect of EtOH history on 5-CSRTT behavior and neurotransmitter levels during the challenge task was examined using RM ANOVA with time (six 5 min bins) as the within-subjects factor and group (CON, $\mathrm{EtOH}$ ) as the between-subjects factor. We used a one-step false discovery rate (FDR) analysis (Benjamini and Hochberg, 1995; Pike, 2011) to correct $p$ values obtained from ANOVAs of individual neurotransmitters for multiple comparisons. The FDR adjustment was applied after grouping the neurotransmitters into three groups based on our original hypothesis (NMDA agonists, monoamines, and other neurotransmitters). Reported $p$ values in text represent corrected values. Associations between dialysate neurotransmitter levels and premature responses were evaluated by Pearson's correlation followed by one-sided significance tests. The effects of intra-vmPFC drug infusions on challenge 5-CSRTT performance were examined by three-way RM ANOVA with group and treatment as between-subjects factors and ITI level as the within-subjects factor. The Greenhouse-Geisser correction was used for all RM ANOVAs when sphericity assumptions were violated, and $F$ values in the text represent the corrected values. Significant interactions were followed by simple effects ANOVA and Student's $t$ test. Data are presented as the mean \pm SEM. In all cases, the criterion for significance was as follows: ${ }^{*} p<$ $0.05,{ }^{* *} p<0.01,{ }^{* * *} p<0.001$. Lack of significance was noted as "NS" (nonsignificant).

\section{Results}

Long-term ethanol exposure does not affect standard task performance To evaluate the effect of long-term EtOH exposure on motor impulsivity, rats (CON, $n=14$; EtOH, $n=13$ ) were trained to perform a standard 5-CSRTT that required them to wait for a fixed amount of time (5s) until they could respond in the appropriate aperture for a reward (Fig. 1). Behavioral indices of standard task performance before $\mathrm{EtOH}$ exposure did not differ between the two groups (CON vs pre-EtOH: $F_{(1,26)}<3.2$, NS; $p>0.08$, NS for all parameters). The EtOH group sustained average BALs of $296 \pm 18 \mathrm{mg} \%$ during long-term EtOH vapor exposure, yet, consistent with prior observations (Walker et al., 2011; Irimia et al., 2014), no significant group differences in standard performance were evident during a 3 week post-EtOH period ( $\mathrm{CON}$ vs EtOH: $F_{(1,25)}<$ 3.9, NS; $p>0.06$, NS for all parameters).

Baseline neurotransmitter levels before the challenge five-choice session

To evaluate the effect of long-term EtOH exposure on cognitive performance, $\mathrm{CON}$ and $\mathrm{EtOH}$ rats were tested on a challenging version of the 5-CSRTT 4 weeks into abstinence. Neurotransmit-
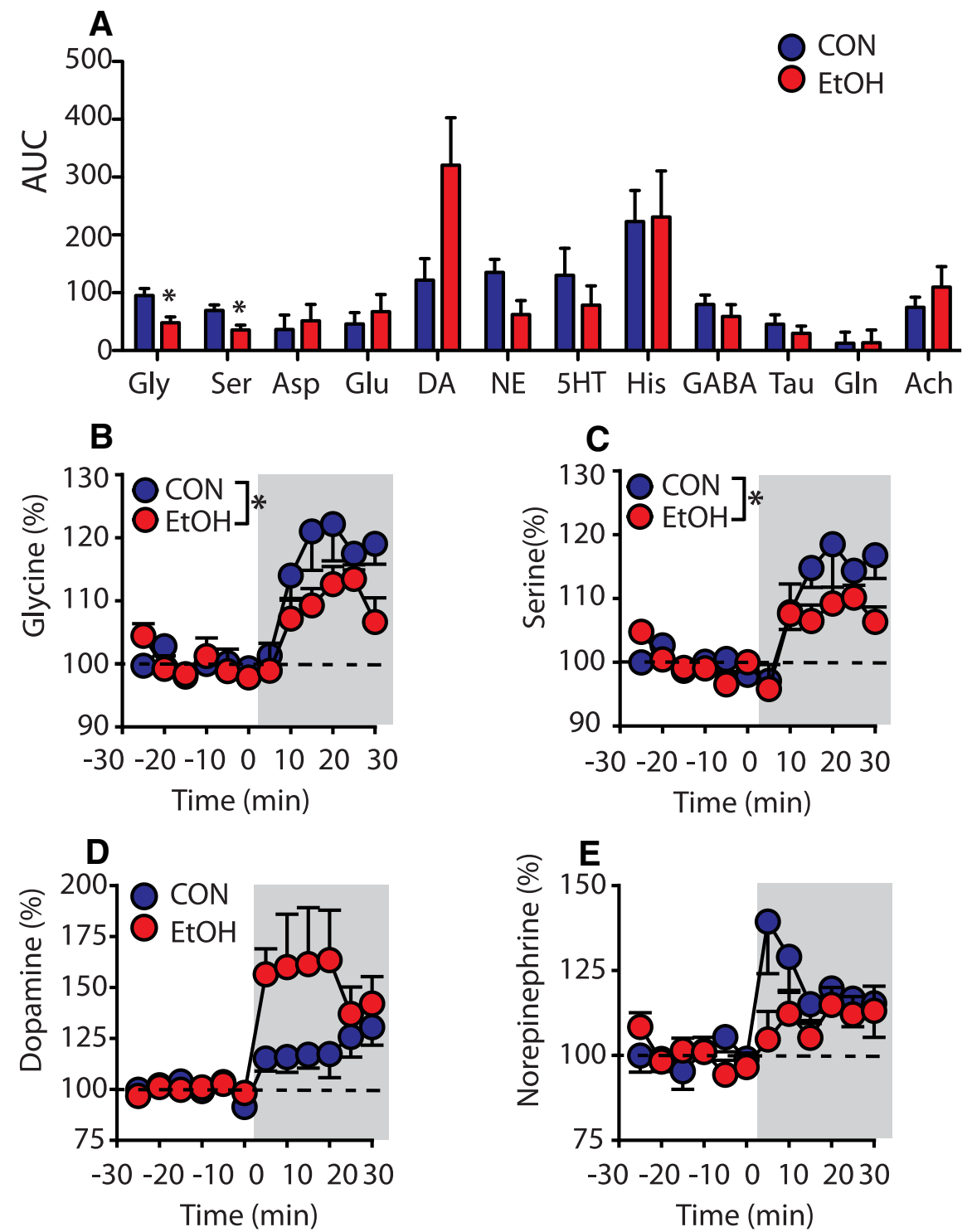

Figure 3. Challenge 5-CSRTT differentially recruits neurotransmitters in the vmPFC of CON and EtOH rats. $\boldsymbol{A}-\boldsymbol{C}$, An unbiased LC-MS/MS analysis of the levels of 12 neurotransmitters in the vmPFC during the performance of the challenge 5-CSRTT $(\boldsymbol{A})$ found blunted release of glycine $(\boldsymbol{B})$ and serine $(\boldsymbol{C})$ in EtOH rats $(n=13)$ compared with CON rats $(n=14)$. $\boldsymbol{D}, \boldsymbol{E}$, EtOH rats showed a trend toward increased dopamine release $(p=0.051 ; D)$ and a reduced initial burst of norepinephrine compared with CON rats ( $p=$ samples were collected from $t=0-30 \mathrm{~min}$. Samples collected during the 5-CSRTT session are shown on a light gray background. AUC values for individual neurotransmitters were calculated by summing the relative change from baseline in each of the six samples collected during the session. ${ }^{*} p<0.05$ and ${ }^{* *} p<0.01$.

ter release in the vmPFC before and during the performance of the challenge task was measured using in vivo microdialysis. Baseline samples collected before the session showed no group differences in neurotransmitter content $\left(F_{(1,26)}<3.9, p>0.06\right.$ for all neurotransmitters, NS).

Performance of the challenge task changes the neurotransmitter profile in the vmPFC in control rats In $\mathrm{CON}$ rats, neurotransmitter levels in the vmPFC significantly increased during the performance of the challenge task compared with presession baseline levels (CON, dopamine: time, $F_{(11,143)}=$ 3.6, $p=0.028$; norepinephrine: $F_{(11,143)}=3.0, p=0.03$; glycine: $F_{(11,143)}=9.2, p=0.000036$; serine: $F_{(11,143)}=5.9, p=0.005$; GABA: $F_{(11,143)}=3.3, p=0.02$; histamine: $F_{(11,143)}=9.5, p=$ 0.0009 ; taurine: $F_{(11,143)}=3.3, p=0.0009$; Fig. $\left.1 D-J\right)$. 
EtOH rats are more impulsive during the performance of the challenge task

In comparison with $\mathrm{CON}$ rats, $\mathrm{EtOH}$ rats exhibited significantly higher levels of premature responding during the challenge session (Fig. $2 A ; F_{(1,26)}=5.1, p=0.03$ ). No group differences in response accuracy (Fig. $2 B$ ) or other performance indices $\left(F_{(1,26)}<\right.$ 2.9 , NS; $p>0.09$, NS for all other behavioral indices; Fig. $2 C-E$ ) were evident, which is consistent with our prior observations (Irimia et al., 2014, 2015). Although EtOH rats made overall more premature responses during the 5-CSRTT probe session compared with $\mathrm{CON}$ rats, there was no significant change over time in the number of premature responses elicited (Fig. $2 F$; premature responses: time: $F_{(5,125)}=1.4, p=0.22$, NS; time $\times$ group interaction, $\left.F_{(5,125)}=1.5, p=0.18, \mathrm{NS}\right)$.

\section{Long-term ethanol exposure reduces release of NMDA} coagonists glycine and serine during the challenge task To evaluate potential alcohol-induced disruptions in signaling that drive impulsivity, we compared neurotransmitter release between $\mathrm{CON}$ and $\mathrm{EtOH}$ rats during the challenge task performance in the vmPFC (Fig. $3 A-E$ ). Rats previously exposed to EtOH exhibited blunted vmPFC release of the NMDA coagonists glycine and serine (CON vs EtOH: glycine: $F_{(1,25)}=8.6, p=0.02$; serine: $F_{(1,25)}=6.8, p=0.03$; Fig. $\left.3 B, C\right)$. There was a trend toward increased vmPFC dopamine levels and reduced norepinephrine levels in $\mathrm{EtOH}$ rats compared with $\mathrm{CON}$ rats that, although significant in individual ANOVAs, was no longer significant after adjusting $p$ values to account for repeated comparisons (CON vs EtOH: dopamine, $F_{(1,25)}=5.1, p=0.051$; norepinephrine, $F_{(1,25)}=5.0, p=0.051$; Fig. $\left.3 D, E\right)$.

To further investigate the relationship between vmPFC neurochemical responses and motor impulsivity, we constructed a regression model to probe the relationship between dialysate neurotransmitter content and premature responses. The independent variables were each of the neurotransmitter concentration in each of the $5 \mathrm{~min}$ samples for each animal, and the dependent variable was the number of premature responses in the time bin. This model accounted for $48 \%$ of the variance in premature responses by CON rats $\left(r=0.691, R^{2}=0.478, F_{(12,83)}=\right.$ $5.4, p<0.001)$ and $47 \%$ of the variance in premature responses by EtOH rats $\left(r=0.686, R^{2}=0.470, F_{(12,77)}=4.8, p<0.001\right)$. These models explained more of the behavioral variance than previous models restricted to monoamines (Dalley et al., 2002), validating the utility of more comprehensive neurotransmitter evaluations. Probing the influence of individual neurotransmitters selected based on ANOVAs (Fig. 3) revealed significant negative correlations between glycine and serine levels and premature responses during the challenge sessions in CON rats (glycine: $r=-0.204, p<0.05$; serine: $r=-0.182, p<0.05)$ but not in EtOH rats (glycine: $r=-0.056$, NS; serine: $r=0.142$, NS). In contrast, dopamine was positively correlated with premature responses in $\mathrm{EtOH}$ rats, but not $\mathrm{CON}$ rats, during the challenge sessions (EtOH: $r=0.200, p<0.05$; CON: $r=-0.042$, NS). Norepinephrine levels were not correlated with premature responses in either group. Collectively, these results suggest that deficient recruitment of vmPFC glycine and other NMDA coagonists may underlie enhanced impulsivity observed during protracted $\mathrm{EtOH}$ abstinence.

Treatment with a glycine transport inhibitor reduces EtOH-specific impulsivity though the NMDA receptor To test the hypothesis that deficient glycine coactivation of the NMDA receptor contributes to impulsivity during protracted
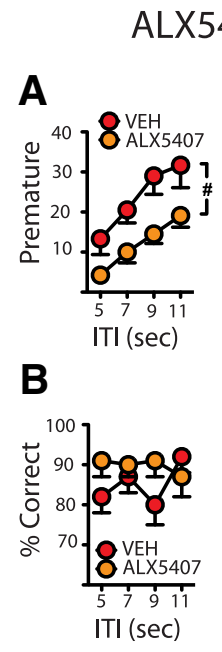

D

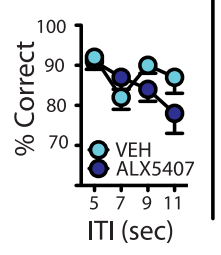

ALX5407+ L-701,324

E

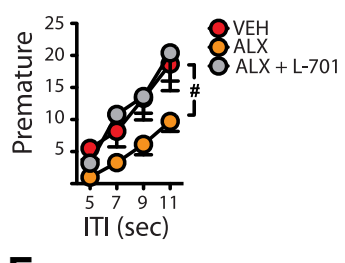

$\mathbf{F}$

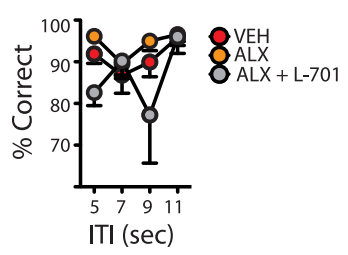

Figure 4. Intra-vmPFC infusion of the glycine transport inhibitor ALX5407 reduces excessive premature responding by $\mathrm{EtOH}$ rats in the challenge task. $\boldsymbol{A}, \boldsymbol{C}$, Following intra-vmPFC VEH infusion EtOH rats $(n=6)$ exhibited significantly more premature responses than $\mathrm{CON}$ rats ( $n=10 ; A, C$. Intra-vmPFC ALX5407 ( $2 \mathrm{ng} /$ side) significantly reduced premature responding by EtOH rats $(n=8 ; \boldsymbol{A})$ without altering premature responding by $\mathrm{CON}$ rats $(n=8 ; \boldsymbol{C}$ ). $\boldsymbol{B}, \boldsymbol{D}$, There was no significant effect of intra-vmPFC ALX5407 on response accuracy in either $\mathrm{EtOH}(\boldsymbol{B})$ or $\mathrm{CON}(\boldsymbol{D})$ rats. $\boldsymbol{E}, \mathrm{ALX} 5407$-induced reductions in premature responding by EtOH rats were reversed by coadministration of the NMDA receptor glycine site $B$ antagonist L-701,324 (2 $\mathrm{ng} /$ side, each; $\mathrm{ALX}, n=7 ; \mathrm{ALX}+\mathrm{L}-701, n=5$; VEH, $n=6$ ). $\boldsymbol{F}$, Coadministration of ALX5407 and L-701,324 did not alter the response accuracy by EtOH rats. ${ }^{\#} p<0.05$.

EtOH abstinence (VEH-treated EtOH vs CON: $F_{(1,14)}=5.4, p=$ 0.032; Fig. $4 A, C$ ), we evaluated the effects of intra-vmPFC infusion of the glycine transport inhibitor ALX5407 (Atkinson et al., 2001) on challenge task performance. The administration of ALX5407 significantly reduced premature responding by EtOH rats (Fig. $4 A$; EtOH, VEH vs ALX5407: $F_{(1,12)}=7.4, p=0.018$ ) to levels observed in vehicle-treated $\mathrm{CON}$ rats (group $\times$ treatment: $F_{(1,28)}=4.4, p=0.044$; Fig. $\left.4 C\right)$. Intra-vmPFC ALX5407 had no effect on premature responding by CON rats (Fig. $4 C$; CON rats: $F_{(1,16)}=1.0, \mathrm{NS}$ ) and did not alter response accuracy (Fig. $4 B, D$ ) or other performance indices in either group. The attenuation of premature responding by $\mathrm{EtOH}$ rats following intra-vmPFC ALX5407 was fully blocked by coadministration of the selective glycine-site NMDA receptor antagonist L-701,324 (Vengeliene et al., 2005; Fig. 4E; effect of pretreatment: $F_{(2,15)}=3.8, p=0.045$; ALX vs VEH: $F_{(1,11)}=4.9, p=0.047$; ALX vs ALX+L701: $F_{(1,10)}=$ 11.6, $p=0.006$; ALX+L701 vs VEH: $F_{(1,9)}<1$, NS), and combined ALX5407 and L-701,324 administration did not significantly alter response accuracy (Fig. 4F) or other indices of challenge task performance. Together, these results demonstrate a functional link between a deficient NMDA coagonist signaling and increased impulsivity during protracted $\mathrm{EtOH}$ abstinence.

\section{$\mathrm{CON}$ and EtOH rats perform a standard 5-CSRTT at similar levels}

A separate group of rats ( $\mathrm{CON}, n=6$; EtOH, $n=6$ ) acquired the standard 5-CSRTT. Before undergoing long-term EtOH vapor exposure, $\mathrm{CON}$ and pre-EtOH rats had similar behavioral performance on the standard 5-CSRTT (Con vs pre-EtOH rats: $F_{(1,11)}>2.8, p>0.12$, NS for all parameters). As expected from the experiment described above and previous results (Irimia et al., 2014, 2015), following EtOH exposure CON and EtOH rats performed at similar levels on the standard task throughout 4 weeks of abstinence $\left(F_{(1,10)}>2.5, p>0.142\right.$, NS; for all param- 
A

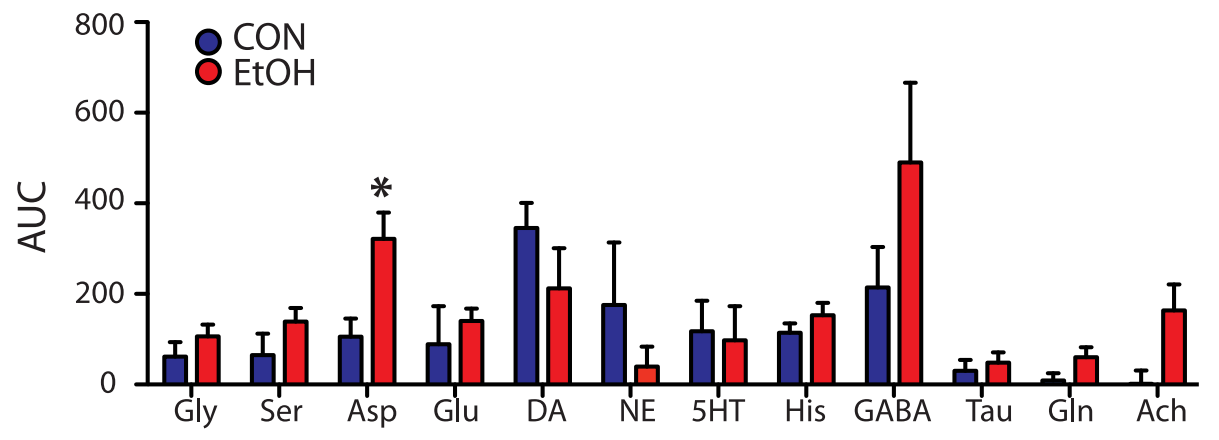

B

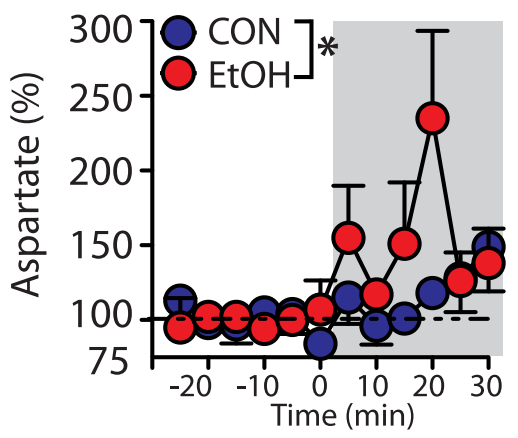

Figure 5. EtOH rats demonstrate increased aspartate levels during the performance of the standard 5-CSRTT. $A, B$, In vivo microdialysis sampling and LC-MS/MS analysis of samples collected while $\mathrm{CON}(n=6)$ and EtOH $(n=6)$ rats were performing a standard 5-CSRTT session $(\boldsymbol{A})$ showed that EtOH rats had significantly higher levels of aspartate compared with CON rats $(\boldsymbol{B})$. Neurotransmitter temporal profiles show the percentage change from baseline during the 5-CSRTT session. Samples collected during the 5-CSRTT session are shown on a light gray background.

eters with the exception of latency to correct response: $F_{(1,10)}=$ $9.5, p=0.012)$. At the end of 4 weeks of abstinence, microdialsyis samples were collected from the vmPFC for $30 \mathrm{~min}$ of baseline values and then for $30 \mathrm{~min}$ as the rats solved a standard 5-CSRTT.

\section{Baseline neurotransmitter levels before a standard five-choice session}

Microdialysis samples collected 30 min before the start of the standard 5-CSRTT showed no difference in baseline levels of neurotransmitters between the two groups $\left(\mathrm{CON}\right.$ vs EtOH: $F_{(1,10)}<1.6$, $p>0.2$, NS). These results mirror the lack of baseline group differences observed in rats before the start of the challenge task.

\section{Long-term ethanol exposure increases release of aspartate during the standard task}

During the standard 5-CSRTT session in which in vivo microdialysis samples were collected from the vmPFC, rats in the CON and EtOH group performed at similar levels, showing no significant group differences in any behavioral index $\left(F_{(1,10)}<2.1\right.$, $p>0.176)$. $\mathrm{CON}$ and $\mathrm{EtOH}$ rats had similar neurotransmitters profiles in vmPFC throughout the session (Fig. $5 A ; F<6.5, p>$ 0.14 , NS for 11 neurotransmitters) with the exception of aspartate, which was significantly elevated in the EtOH group (Fig. $5 B$; $\left.F_{(1,10)}=9.4, p=0.047\right)$.

\section{Discussion}

Rats with long-term ethanol exposure demonstrate improper response inhibition in the 5-CSRTT challenge task (Walker et al., 2011; Irimia et al., 2015). The present study replicates these behavioral observations and reveals that increased motor impulsivity in the EtOH group is associated with diminished recruitment of vmPFC glycine and serine. EtOH-exposed rats do not demonstrate a correlation between levels of glycine and serine and the premature responding that is evident in CON rats. Intra-vmPFC administration of the glycine transport inhibitor ALX5407 ameliorates excessive premature responding by EtOH-exposed rats through a mechanism reliant on the availability of the glycine site on the NMDA receptor. These results indicate that deficient signaling at the NMDA receptor 1 (NR1) coagonist site contributes to increased motor impulsivity during protracted EtOH abstinence.

The relevance of the present observations for the clinical population relies on the strength of the models used to obtain the mechanistic insight. Here, the increase in motor impulsivity in alcoholics was modeled by an increase in premature responses in rats with CIE vapor exposure. Most clinical data on the tasks of response inhibition require inhibition of specific stimuli (Noël, 2012; Stavro et al., 2013), while in the challenge 5-CSRTTs rats made more responses before the presentation of the Go stimulus. However, a recent study (Voon et al., 2014) showed that persons with alcoholism are also deficient in their ability to inhibit prepotent motor responses while solving the 5-CSRTT. CIE exposure through vapor inhalation (Rogers et al., 1979; O'Dell et al., 2004; Gilpin and Koob, 2008) is a valuable model of alcohol dependence as, in rats, prolonged exposure leads to several signs of dependence, such as increased EtOH consumption (Gilpin and Koob, 2008), the presence of withdrawal when the drug is not available (Schulteis et al., 1995), increased likelihood of relapse (Liu and Weiss, 2002), and continued consumption of EtOH despite negative consequences (Vendruscolo et al., 2012).

Glycine has not previously been implicated in modulating impulse control. The importance of NMDA receptor signaling for cognitive processing has long been recognized (Tang et al., 1999), and, due to the role of glycine as an obligatory coagonist for the NMDA receptor, glycine signaling has been evaluated as a therapeutic target to improve cognitive function in pathologic conditions such as schizophrenia (Harvey and Yee, 2013; Young et al., 2015). NMDA receptors also modulate response inhibition (Murphy et al., 2012; Finlay et al., 2015). The present evidence supports and extends these observations by implicating vmPFC glycine signaling at the NMDA coagonist site in the constraint of motor impulsivity. As a coagonist, glycine may improve response inhibition by reversing hypofunctioning states of the NMDA receptor (Coyle, 2006). Serine is also an agonist at the NMDA receptor coagonist site (Araque et al., 2014), and the present finding of blunted serine recruitment during challenge task performance by EtOH-exposed rats suggests a combined influence of deficient glycine and serine signaling in the excessive premature responding elicited by these rats. However, we note that using our analytical procedure, we could not distinguish between D-serine and L-serine. EtOH-naive rats demonstrate impaired impulse control following NMDA antagonism in vmPFC (Murphy et al., 2012), which is blocked by $\mathrm{GABA}_{\mathrm{A}}$ antagonism (Murphy et al., 2012), or following lesions of vmPFC (Chudasama et al., 2003). Thus, impulse control may depend on the balance of excitation and inhibition in the vmPFC circuit (Lisman, 2012; Murphy et al., 2012). Although in the current experiments there were no group differences in GABA levels during the challenge task (Fig. 3), performance of the challenge probe resulted in significantly increased 
GABA levels compared with baseline (Fig. $1 H$ ). A lack of compensatory activation of NMDA receptors by glycine and serine in the $\mathrm{EtOH}$ group could result in increased inhibition of pyramidal cells in vmPFC. The ability of the glycine transporter inhibitor ALX-5407 to improve impulse control in the EtOH group provides further evidence that glycine and serine signaling at the NMDA coagonist site modulated motor impulsivity, although a limitation of the current study is the lack of microdialysis measurements following ALX-5407 infusion, confirming an increase in glycine levels (Perry et al., 2008). Together, the present findings suggest that bolstering NMDA receptor coagonist site occupancy ameliorates post-EtOH increases in motor impulsivity at this protracted abstinence time point.

Diminished expression of NMDA receptor subunits and glycine signaling at the strychnine-sensitive glycine receptors may contribute to excessive premature responding by $\mathrm{EtOH}$-exposed rats. Indeed, reduced NR1 expression in the MPFC emerges during abstinence from long-term EtOH exposure (Holmes et al., 2012; Kroener et al., 2012). In the nucleus accumbens, EtOH perfusion increases dopamine levels, and the effect is blocked by the antagonism of glycine receptors (Jonsson et al., 2014), raising the possibility that, in the current study, reduced glycine levels in the EtOH group may contribute to the trend in increased dopamine and impaired impulse control observed during the challenge task.

Higher levels of premature responses in the EtOH group during the challenge 5-CSRTT session could result from impaired learning in this group. Rats experience the variable ITI for the first time during the challenge 5-CSRTT session, and NMDA receptor function has previously been shown to be important for instrumental learning (Sakimura et al., 1995; Baldwin et al., 2002). However, the lack of an improvement in premature responses with time in CON rats performing the challenge task (Fig. $2 F$ ) does not support an effect of learning in the current experiments. Because previous work (Walker et al., 2011) has shown that $\mathrm{CON}$ rats can learn to restrain premature responses following repeated challenge tests, it is possible that group differences in response inhibition would be exacerbated if $\mathrm{CON}$ and $\mathrm{EtOH}$ rats were given repeated challenge tests closely spaced in time.

Existing evidence demonstrates the therapeutic potential of targeting glycine for alcoholism. Glycine transport inhibition or D-cycloserine administration (a glycine-B site agonist) reduces the positive effects of EtOH, enhances the extinction of ethanolrelated cues, and reduces the hyperglutamatergic state associated with alcoholism (Trevisan et al., 2008; Vengeliene et al., 2008, 2010; Spanagel, 2009; Lidö et al., 2012; Holmes et al., 2013; Seif et al., 2015). The present findings suggest that these therapeutic approaches may additionally improve impulse control under conditions of enhanced cognitive load, a capacity that is impaired in individuals with problematic alcohol use (Moselhy et al., 2001; Noël et al., 2001; Jung et al., 2014) and may contribute to heightened risk of relapse (Bowden-Jones et al., 2005; MacKillop and Kahler, 2009; Loree et al., 2015).

The present analytical approach allowed the novel unbiased evaluation of parallel neurotransmitter changes needed to characterize complex cognitive functions that engage multiple signaling systems. For example, we found that performance in the 5-CSRTT challenge session by naive rats led to the cortical release of GABA, taurine, and histamine (Fig. $1 H-J$ ). Infusion of $\mathrm{GABA}_{\mathrm{A}}$ agonists in the vmPFC increases premature responses during 5-CSRTT baseline sessions (Murphy et al., 2012), suggesting that behavioral inhibition can be modulated through GABA receptors in the vmPFC cortex. Taurine levels correlate with behavioral inhibition as evaluated by the Stroop test in schizophrenic patients (Shirayama et al., 2010). Increased histamine release supports a proposed role for this neurotransmitter in promoting wakefulness (Passani et al., 2014). Together, these findings highlight the overall neurochemical diversity underlying complex behaviors, such as impulsivity, and the importance of evaluating cortical dysfunction using a comprehensive analytical approach.

Neuroimaging studies suggest that in persons with alcoholism the recruitment of compensatory cortical mechanisms serves to sustain control levels of cognitive task performance (Li et al., 2009; Chanraud et al., 2013; Jung et al., 2014). In the present experiments, $\mathrm{EtOH}$-exposed and $\mathrm{CON}$ rats exhibited comparable performance of the standard 5-CSRTT, although EtOHexposed rats displayed significantly greater recruitment of vmPFC aspartate during this task. Aspartate is a weak NMDA receptor coagonist (Patneau and Mayer, 1990), and robust elevations in vmPFC aspartate levels may serve to sustain NMDA receptor signaling in EtOH-exposed rats during standard 5-CSRTT performance. However, this group difference in aspartate recruitment is lost during the challenge task, which, together with deficient recruitment of glycine and serine, may contribute to impaired motor impulsivity.

In summary, the present data provide evidence that increased motor impulsivity during protracted $\mathrm{EtOH}$ abstinence is associated with deficient recruitment of glycine and serine release in the vmPFC, and that bolstering NMDA receptor coagonist site activation through intra-vmPFC administration of a glycine uptake inhibitor ameliorates $\mathrm{EtOH}$-related increases in premature responding. These results shed new light on the possible therapeutic benefits of glycine transport inhibitors for alcohol use disorders and alcoholism. Furthermore, our unbiased LC-MS/MS approach allowed us to provide a comprehensive picture of the changes in neurotransmitter levels associated with the performance of the challenge 5-CSRTT.

\section{References}

Araque A, Carmignoto G, Haydon PG, Oliet SH, Robitaille R, Volterra A (2014) Gliotransmitters travel in time and space. Neuron 81:728-739. CrossRef Medline

Atkinson BN, Bell SC, De Vivo M, Kowalski LR, Lechner SM, Ognyanov VI, Tham CS, Tsai C, Jia J, Ashton D, Klitenick MA (2001) ALX 5407: a potent, selective inhibitor of the hGlyT1 glycine transporter. Mol Pharmacol 60:1414-1420. CrossRef Medline

Baldwin AE, Sadeghian K, Kelley AE (2002) Appetitive instrumental learning requires coincident activation of NMDA and dopamine D1 receptors within the medial prefrontal cortex. J Neurosci 22:1063-1071. Medline

Benjamini Y, Hochberg Y (1995) Controlling the false discovery rate: a practical and powerful approach to multiple testing. J R Stat Soc Series B Stat Methodol 57:289-300.

Bowden-Jones H, McPhillips M, Rogers R, Hutton S, Joyce E (2005) Risktaking on tests sensitive to ventromedial prefrontal cortex dysfunction predicts early relapse in alcohol dependency: a pilot study. J Neuropsychiatry Clin Neurosci 17:417-420. CrossRef Medline

Buczynski MW, Herman MA, Hsu KL, Natividad LA, Irimia C, Polis IY, Pugh H, Chang JW, Niphakis MJ, Cravatt BF, Roberto M, Parsons LH (2016) Diacylglycerol lipase disinhibits VTA dopamine neurons during chronic nicotine exposure. Proc Natl Acad Sci U S A 113:1086-1091. CrossRef Medline

Caillé S, Alvarez-Jaimes L, Polis I, Stouffer DG, Parsons LH (2007) Specific alterations of extracellular endocannabinoid levels in the nucleus accumbens by ethanol, heroin, and cocaine self-administration. J Neurosci 27: 3695-3702. CrossRef Medline

Chanraud S, Pitel AL, Müller-Oehring EM, Pfefferbaum A, Sullivan EV (2013) Remapping the brain to compensate for impairment in recovering alcoholics. Cereb Cortex 23:97-104. CrossRef Medline

Chudasama Y, Passetti F, Rhodes SE, Lopian D, Desai A, Robbins TW (2003) 
Dissociable aspects of performance on the 5-choice serial reaction time task following lesions of the dorsal anterior cingulate, infralimbic and orbitofrontal cortex in the rat: differential effects on selectivity, impulsivity and compulsivity. Behav Brain Res 146:105-119. CrossRef Medline

Coyle JT (2006) Glutamate and schizophrenia: beyond the dopamine hypothesis. Cell Mol Neurobiol 26:363-382. CrossRef Medline

Crews FT, Boettiger CA (2009) Impulsivity, frontal lobes and risk for addiction. Pharmacol Biochem Behav 93:237-247. CrossRef Medline

Crews FT, Nixon K (2009) Mechanisms of neurodegeneration and regeneration in alcoholism. Alcohol Alcohol 44:115-127. CrossRef Medline

Dalley JW, Theobald DE, Eagle DM, Passetti F, Robbins TW (2002) Deficits in impulse control associated with tonically-elevated serotonergic function in rat prefrontal cortex. Neuropsychopharmacology 26:716-728. CrossRef Medline

Duka T, Townshend JM, Collier K, Stephens DN (2003) Impairment in cognitive functions after multiple detoxifications in alcoholic inpatients. Alcohol Clin Exp Res 27:1563-1572. CrossRef Medline

Duka T, Crombag HS, Stephens DN (2011a) Experimental medicine in drug addiction: towards behavioral, cognitive and neurobiological biomarkers. J Psychopharmacol 25:1235-1255. CrossRef Medline

Duka T, Trick L, Nikolaou K, Gray MA, Kempton MJ, Williams H, Williams SC, Critchley HD, Stephens DN (2011b) Unique brain areas associated with abstinence control are damaged in multiply detoxified alcoholics. Biol Psychiatry 70:545-552. CrossRef Medline

Fein G, Di Sclafani V, Cardenas VA, Goldmann H, Tolou-Shams M, Meyerhoff DJ (2002) Cortical gray matter loss in treatment-naïve alcohol dependent individuals. Alcohol Clin Exp Res 26:558-564. CrossRef Medline

Finlay JM, Dunham GA, Isherwood AM, Newton CJ, Nguyen TV, Reppar PC, Snitkovski I, Paschall SA, Greene RW (2015) Effects of prefrontal cortex and hippocampal NMDA-NR1 subunit deletion on complex cognitive and social behaviors. Brain Res 1600:70-83. CrossRef Medline

George O, Koob G, Vendruscolo L (2014) Negative reinforcement via motivational withdrawal is the driving force behind the transition to addiction. Psychopharmacology (Berl) 231:3911-3917. CrossRef Medline

Gilpin NW, Koob GF (2008) Neurobiology of alcohol dependence: focus on motivational mechanisms. Alcohol Res Health 31:185-195. Medline

Goldstein RZ, Volkow ND (2011) Dysfunction of the prefrontal cortex in addiction: neuroimaging findings and clinical implications. Nat Rev Neurosci 12:652-669. CrossRef Medline

Harvey RJ, Yee BK (2013) Glycine transporters as novel therapeutic targets in schizophrenia, alcohol dependence and pain. Nat Rev Drug Discov 12:866-885. CrossRef Medline

Holmes A, Fitzgerald PJ, MacPherson KP, DeBrouse L, Colacicco G, Flynn SM, MasneufS, Pleil KE, Li C, Marcinkiewcz CA, Kash TL, Gunduz-Cinar O, Camp M (2012) Chronic alcohol remodels prefrontal neurons and disrupts NMDAR-mediated fear extinction encoding. Nat Neurosci 15: 1359-1361. CrossRef Medline

Holmes A, Spanagel R, Krystal JH (2013) Glutamatergic targets for new alcohol medications. Psychopharmacology (Berl) 229:539-554. CrossRef Medline

Irimia C, Tuong RN, Quach T, Parsons LH (2014) Impaired response inhibition in the rat 5 choice continuous performance task during protracted abstinence from chronic alcohol consumption. PLoS One 9:e109948. CrossRef Medline

Irimia C, Wiskerke J, Natividad LA, Polis IY, de Vries TJ, Pattij T, Parsons LH (2015) Increased impulsivity in rats as a result of repeated cycles of alcohol intoxication and abstinence. Addict Biol 20:263-274. CrossRef Medline

Iversen SD, Mishkin M (1970) Perseverative interference in monkeys following selective lesions of the inferior prefrontal convexity. Exp Brain Res 11:376-386. Medline

Jentsch JD, Taylor JR (1999) Impulsivity resulting from frontostriatal dysfunction in drug abuse: implications for the control of behavior by rewardrelated stimuli. Psychopharmacology (Berl) 146:373-390. CrossRef Medline

Jonsson S, Adermark L, Ericson M, Söderpalm B (2014) The involvement of accumbal glycine receptors in the dopamine-elevating effects of addictive drugs. Neuropharmacology 82:69-75. CrossRef Medline

Jung Y-C, Schulte T, Müller-Oehring EM, Namkoong K, Pfefferbaum A, Sullivan EV (2014) Compromised frontocerebellar circuitry contributes to nonplanning impulsivity in recovering alcoholics. Psychopharmacology (Berl) 231:4443-4453. CrossRef Medline

Kamarajan C, Porjesz B, Jones KA, Choi K, Chorlian DB, Padmanabhapillai
A, Rangaswamy M, Stimus AT, Begleiter H (2005) Alcoholism is a disinhibitory disorder: neurophysiological evidence from a go/no-go task. Biol Psychol 69:353-373. CrossRef Medline

Kroener S, Mulholland PJ, New NN, Gass JT, Becker HC, Chandler LJ (2012) Chronic alcohol exposure alters behavioral and synaptic plasticity of the rodent prefrontal cortex. PLoS One 7:e37541. CrossRef Medline

Lawrence AJ, Luty J, Bogdan NA, Sahakian BJ, Clark L (2009) Impulsivity and response inhibition in alcohol dependence and problem gambling. Psychopharmacology (Berl) 207:163-172. CrossRef Medline

Li CS, Luo X, Yan P, Bergquist K, Sinha R (2009) Altered impulse control in alcohol dependence: neural measures of stop signal performance. Alcohol Clin Exp Res 33:740-750. CrossRef Medline

Lidö HH, Marston H, Ericson M, Söderpalm B (2012) The glycine reuptake inhibitor Org24598 and acamprosate reduce ethanol intake in the rat; tolerance development to acamprosate but not to Org24598. Addict Biol 17:897-907. CrossRef Medline

Lisman J (2012) Excitation, inhibition, local oscillations, or large-scale loops: what causes the symptoms of schizophrenia? Curr Opin Neurobiol 22:537-544. CrossRef Medline

Liu X, Weiss F (2002) Additive effect of stress and drug cues on reinstatement of ethanol seeking: exacerbation by history of dependence and role of concurrent activation of corticotropin-releasing factor and opioid mechanisms. J Neurosci 22:7856-7861. Medline

Loree AM, Lundahl LH, Ledgerwood DM (2015) Impulsivity as a predictor of treatment outcome in substance use disorders: review and synthesis. Drug Alcohol Rev 34:119-134. CrossRef Medline

MacKillop J, Kahler CW (2009) Delayed reward discounting predicts treatment response for heavy drinkers receiving smoking cessation treatment. Drug Alcohol Depend 104:197-203. CrossRef Medline

Moos RH, Moos BS (2006) Rates and predictors of relapse after natural and treated remission from alcohol use disorders. Addiction 101:212-222. CrossRef Medline

Moselhy HF, Georgiou G, Kahn A (2001) Frontal lobe changes in alcoholis: a review of the literature. Alcohol Alcohol 36:357-368. CrossRef Medline

Murphy ER, Fernando AB, Urcelay GP, Robinson ES, Mar AC, Theobald DE, Dalley JW, Robbins TW (2012) Impulsive behaviour induced by both NMDA receptor antagonism and GABAA receptor activation in rat ventromedial prefrontal cortex. Psychopharmacology (Berl) 219:401-410. CrossRef Medline

Noël X (2012) Alcoholism: an impulsive/disinhibition disorder? In: Psychologyselected papers (Rossi G, ed), pp 21-36. Rijeka, Croatia: InTech.

Noël X, Van der Linden M, Schmidt N, Sferrazza R, Hanak C, Le Bon O, De Mol J, Kornreich C, Pelc I, Verbanck P (2001) Supervisory attentional system in nonamnesic alcoholic men. Arch Gen Psychiatry 58:1152-1158. CrossRef Medline

O'Dell LE, Roberts AJ, Smith RT, Koob GF (2004) Enhanced alcohol selfadministration after intermittent versus continuous alcohol vapor exposure. Alcohol Clin Exp Res 28:1676-1682. CrossRef Medline

Passani MB, Panula P, Lin JS (2014) Histamine in the brain. Front Syst Neurosci 8:64. CrossRef Medline

Patneau DK, Mayer ML (1990) Structure-activity relationships for amino acid transmitter candidates acting at $N$-methyl-D-aspartate and quisqualate receptors. J Neurosci 10:2385-2399. Medline

Perry KW, Falcone JF, Fell MJ, Ryder JW, Yu H, Love PL, Katner J, Gordon KD, Wade MR, Man T, Nomikos GG, Phebus LA, Cauvin AJ, Johnson KW, Jones CK, Hoffmann BJ, Sandusky GE, Walter MW, Porter WJ, Yang L, et al. (2008) Neurochemical and behavioral profiling of the selective GlyT1 inhibitors ALX5407 and LY2365109 indicate a preferential action in caudal vs. cortical brain areas. Neuropharmacology 55:743-754. CrossRef Medline

Pike N (2011) Using false discovery rates for multiple comparisons in ecology and evolution. Methods Ecol Evol 2:278-282. CrossRef

Rogers J, Wiener SG, Bloom FE (1979) Long-term ethanol administration methods for rats: advantages of inhalation over intubation or liquid diets. Behav Neural Biol 27:466-486. CrossRef Medline

Rubio G, Jiménez M, Rodríguez-Jiménez R, Martínez I, Avila C, Ferre F, Jiménez-Arriero MA, Ponce G, Palomo T (2008) The role of behavioral impulsivity in the development of alcohol dependence: a 4-year follow-up study. Alcohol Clin Exp Res 32:1681-1687. CrossRef Medline

Sakimura K, Kutsuwada T, Ito I, Manabe T, Takayama C, Kushiya E, Yagi T, Aizawa S, Inoue Y, Sugiyama H (1995) Reduced hippocampal LTP and 
spatial learning in mice lacking NMDA receptor 1 subunit. Nature 373: 151-155. CrossRef Medline

Salgado JV, Malloy-Diniz LF, Campos VR, Abrantes SS, Fuentes D, Bechara A, Correa H (2009) Neuropsychological assessment of impulsive behavior in abstinent alcohol-dependent subjects. Rev Bras Psiquiatr 31:4-9. CrossRef Medline

Sanchez-Roige S, Baro V, Trick L, Peña-Oliver Y, Stephens DN, Duka T (2014) Exaggerated waiting impulsivity associated with human binge drinking, and high alcohol consumption in mice. Neuropsychopharmacology 39:2919-2927. CrossRef Medline

Schulteis G, Markou A, Cole M, Koob GF (1995) Decreased brain reward produced by ethanol withdrawal. Proc Natl Acad Sci U S A 92:58805884. CrossRef Medline

Seif T, Simms JA, Lei K, Wegner S, Bonci A, Messing RO, Hopf FW (2015) $\mathrm{D}$-serine and D-cycloserine reduce compulsive alcohol intake in rats. Neuropsychopharmacology 40:2357-2367. CrossRef Medline

Shirayama Y, Obata T, Matsuzawa D, Nonaka H, Kanazawa Y, Yoshitome E, Ikehira H, Hashimoto K, Iyo M (2010) Specific metabolites in the medial prefrontal cortex are associated with the neurocognitive deficits in schizophrenia: a preliminary study. Neuroimage 49:2783-2790. CrossRef Medline

Song P, Mabrouk OS, Hershey ND, Kennedy RT (2012) In vivo neurochemical monitoring using benzoyl chloride derivatization and liquid chromatography-mass spectrometry. Anal Chem 84:412-419. CrossRef Medline

Spanagel R (2009) Alcoholism: a systems approach from molecular physiology to addictive behavior. Physiol Rev 89:649-705. CrossRef Medline

Stavro K, Pelletier J, Potvin S (2012) Widespread and sustained cognitive deficits in alcoholism: a meta-analysis. Addict Biol 18:203-213. CrossRef Medline

Sullivan EV, Pfefferbaum A (2005) Neurocircuitry in alcoholism: a substrate of disruption and repair. Psychopharmacology (Berl) 180:583-594. CrossRef

Swick D, Ashley V, Turken U (2011) Are the neural correlates of stopping and not going identical? Quantitative meta-analysis of two response inhibition tasks. Neuroimage 56:1655-1665. CrossRef Medline

Tang YP, Shimizu E, Dube GR, Rampon C, Kerchner GA, Zhuo M, Liu G,
Tsien JZ (1999) Genetic enhancement of learning and memory in mice. Nature 401:63-69. CrossRef Medline

Trevisan L, Petrakis IL, Pittman B, Gueorguieva R, D’Souza DC, Perry E, Limoncelli D, Krystal JH (2008) Absence of significant interactive effects of high-dose d-cycloserine and ethanol in healthy human subjects: preliminary insights into ethanol actions at the GlycineB site of NMDA glutamate receptors. Alcohol Clin Exp Res 32:36-42. CrossRef Medline

Vendruscolo LF, Barbier E, Schlosburg JE, Misra KK, Whitfield TW Jr, Logrip ML, Rivier C, Repunte-Canonigo V, Zorrilla EP, Sanna PP, Heilig M, Koob GF (2012) Corticosteroid-dependent plasticity mediates compulsive alcohol drinking in rats. J Neurosci 32:7563-7571. CrossRef Medline

Vengeliene V, Bachteler D, Danysz W, Spanagel R (2005) The role of the NMDA receptor in alcohol relapse: a pharmacological mapping study using the alcohol deprivation effect. Neuropharmacology 48:822-829. CrossRef Medline

Vengeliene V, Kiefer F, Spanagel R (2008) D-cycloserine facilitates extinction of conditioned alcohol-seeking behaviour in rats. Alcohol Alcohol 43:626-629. CrossRef Medline

Vengeliene V, Leonardi-Essmann F, Sommer WH, Marston HM, Spanagel R (2010) Glycine transporter-1 blockade leads to persistently reduced relapselike alcohol drinking in rats. Biol Psychiatry 68:704-711. CrossRef Medline

Voon V, Irvine MA, Derbyshire K, Worbe Y, Lange I, Abbott S, MoreinZamir S, Dudley R, Caprioli D, Harrison NA, Wood J, Dalley JW, Bullmore ET, Grant JE, Robbins TW (2014) Measuring "waiting" impulsivity in substance addictions and binge eating disorder in a novel analogue of rodent serial reaction time task. Biol Psychiatry 75:148-155. CrossRef Medline

Walker SE, Peña-Oliver Y, Stephens DN (2011) Learning not to be impulsive: disruption by experience of alcohol withdrawal. Psychopharmacology (Berl) 217:433-442. CrossRef Medline

Weafer J, Mitchell SH, de Wit H (2014) Recent translational findings on impulsivity in relation to drug abuse. Curr Addict Rep 1:289-300. CrossRef Medline

Young JW, Kamenski ME, Higa KK, Light GA, Geyer MA, Zhou X (2015) GlyT-1 inhibition attenuates attentional but not learning or motivational deficits of the Sp4 hypomorphic mouse model relevant to psychiatric disorders. Neuropsychopharmacology 40:2715-2726. CrossRef Medline 